\title{
Lewandowski \& Lutz Syndrome: A Rare Case Entity
}

\author{
Mohan $\mathbf{R}^{1}$, Gahalaut $\mathrm{P}^{2}$, Soodan $\mathrm{HS}^{2}$, Mishra $\mathbf{N}^{3}$, Rastogi $\mathbf{M N}^{4}$ \\ ${ }^{1}$ Resident, ${ }^{2}$ Professor \& Head of Department, ${ }^{3}$ Associate Professor, ${ }^{4}$ Assistant Professor, Department of Dermatology, \\ Venereology and Leprosy, Shri Ram Murti Smarak Institute of Medical Sciences.
}

\begin{abstract}
Epidermodysplasia verruciformis (EV), first described in 1922 by Lewandowski and Lutz, is a rare inherited genetic disease. The disease usually manifests in childhood with highly polymorphic, widespread lesions. ${ }^{1}$

We report a case of a fifteen year old boy, who presented to us with multiple flat topped, hypopigmented papules of a seven year duration on his body. He was diagnosed with EV on a skin biopsy, after ruling out differential diagnosis of pityriasis versicolor, verruca vulgaris and acrokeratosisverruciformis. The patient was resistant to known treatment options.
\end{abstract}

Key message: sun protection and lifelong observation for diagnosis and improved prognosis of malignant or premalignant lesions of EV.

Key words: pityriasis versicolor, verruca-like lesions, sun exposed sites

\section{Introduction}

$E_{8}^{p}$ pidermodysplasia verruciformis is a rare genodermatosis characterized by a unique susceptibility to cutaneous infection by a group of phylogenetically related human papilloma viruses (EV-HPVs). ${ }^{2}$ These patients show a defect in cellmediated immunity specific toward the causative HPV that lead to lifelong disease. The defect is usually inherited as autosomal recessive trait and presents clinically with plane warts, pityriasis versicolor-like lesions and reddish verrucous plaques. Dysplastic and malignant changes in the form of actinic keratoses, Bowen's disease and squamous cell carcinoma (SCC) are common but metastasis occurs rarely. A totally effective treatment against EV is as yet highly desirable. The mode of inheritance is often autosomal recessive and a mutation in EVER1 or EVER2 genes located in chromosome 17 causes underlying cell mediated immune deficiency. ${ }^{3}$ We are presenting a case of EV in a 15 year old male patient, to document and share our clinico-therapeutic experience.

\section{Conflict of Interest: No}

Address for correspondence
Dr. Rikta Mohan
101, Sri Ram Niwas
I.I.T. Market, Powai, Mumbai
pin code- 400076.
Phone no. 7533827073
E-mail: rikta.mohan@gmail.com

Dr. Rikta Mohan

101, Sri Ram Niwas

pin code- 400076

E-mail: rikta.mohan@gmail.com

\section{Case Discussion}

A fifteen year old boy (Figure.1) presented with raised hypopigmented, flat-topped, non pruritic, non tender, wart-like, slowly progressive skin eruptions on the whole body since the last seven years. The lesions initially presented on the forehead and gradually progressed in a caudal direction, to involve most of the body in a span of seven years. He was otherwise normal clinically. No other family members had similar complaints. All the baseline investigations including complete blood count, liver function tests, and lipid profile and serological test for HIV were normal.

Pityriasis versicolor was ruled out with a potassium hydroxide of the lesional skin scrapings. A differential diagnosis of Acrokeratosisverruciformis and Verruca Vulgaris were made.

Skin biopsy from one of the lesions showed (Fig.2a,2b,2c) diffuse vacuolization, swelling and numerous round, basophilic keratohyalin granules in the stratum Malpighi, and granular layer.

The patient was unresponsive to treatment (Fig.3), with daily $10 \mathrm{mg}$ Acitretin, sunscreen, topical azelaic acid and zinc supplements, even after five months duration.

Though, the patient's lesions didn't seem to be progressive in nature, they also appeared to be resistant to the given treatment. No side effects were 
reported by our patient during therapy or follow-up. All the oral medications were stopped and patient was advised to continue sun protection. He is under regular follow up and the lesions are non-progressive presently.

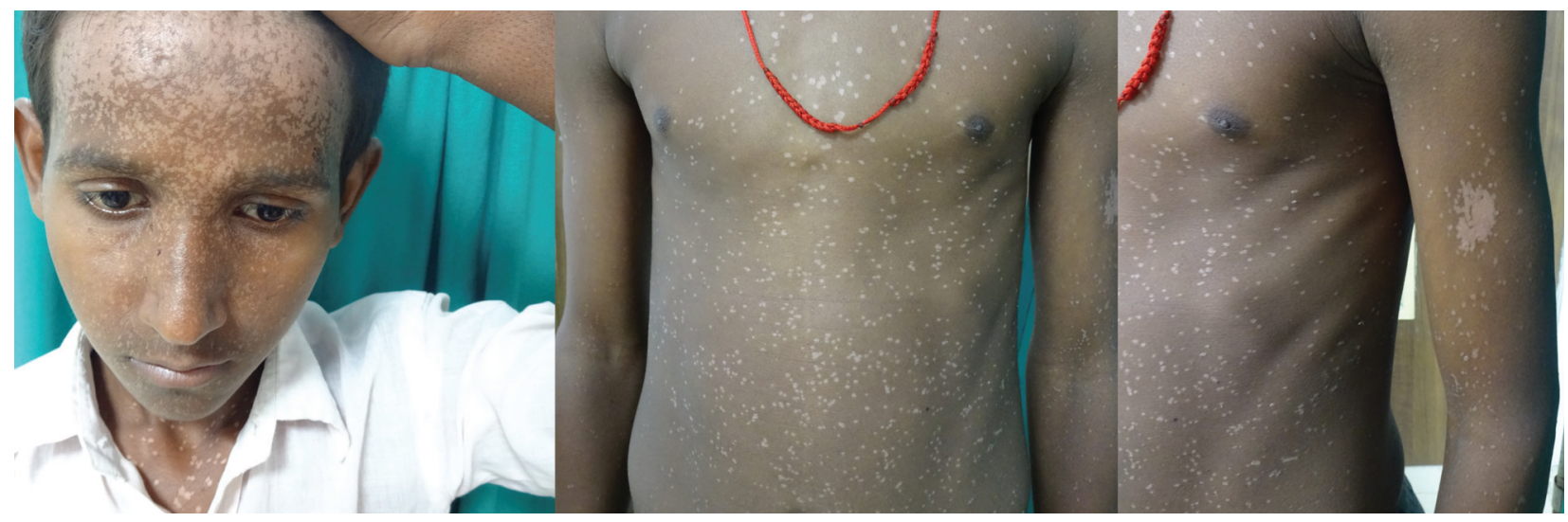

Figure 1 : Initial presentation of patient

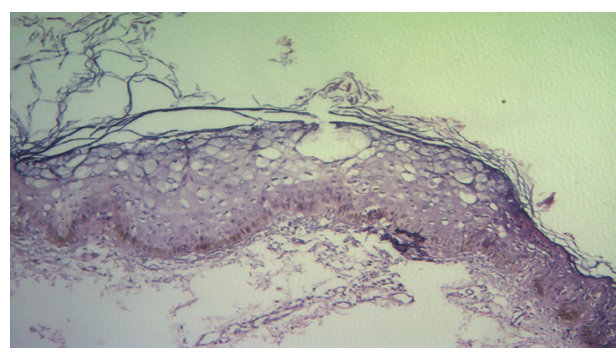

Figure 2a: H\&E stain (40x magnification) showing acanthosis in the stratum Malpighi, and diffuse vacuolization of the cells in the granular layer.

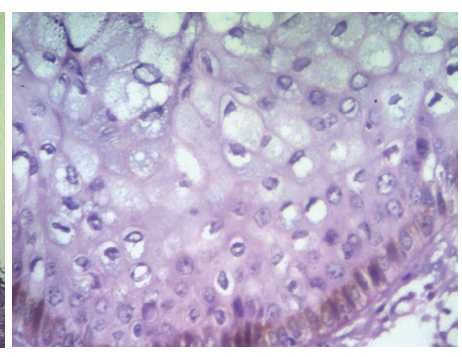

Figure 2b: H\&E stain (100x magnification) showing few cells in the granular layer with pyknotic nuclei and other cells have nuclei that are round empty with peripherally keratohyalin granules condensed chromatin.

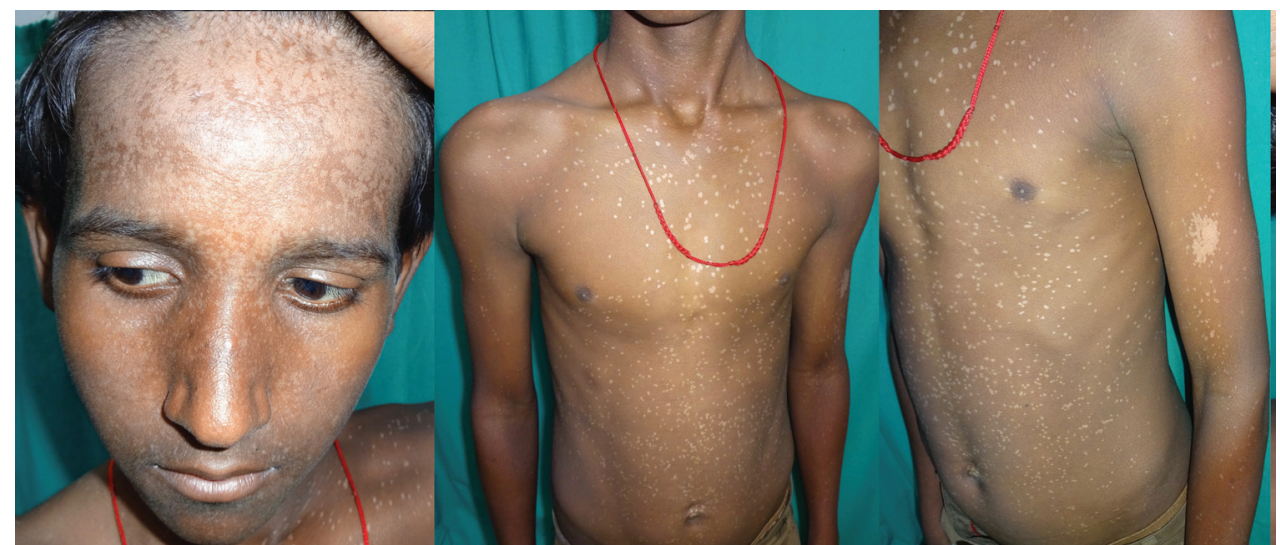

Figure 3 : the patient, five months after treatment 


\section{Discussion}

Clinically, it presents with a characteristic combination of pityriasis versicolor-like lesions, reddish verruca-like and seborrheic keratosis-like plaques with a potential for malignant transformation. ${ }^{2} \mathrm{EV}$ is characterized by widespread human papilloma virus (HPV) infection. ${ }^{4}$ HPV 5 and 8 are the main types incriminated for the malignant transformation in about $25 \%$ of EV patients. ${ }^{5-7} \mathrm{EV}$ occurs worldwide but doesn't display any gender or geographic predisposition. Its frequency is $11 \%$ in Europe and USA and $40 \%$ among Japanese, ${ }^{8}$ but reported infrequently from India. A PubMed and IndMed search on 26 Oct 2009 revealed only 12 reports appearing between 1971 and 2009 . $^{8-11}$

The disease has no preference for gender or race and can be sporadic or familial. The disease usually begins in childhood. The hallmark lesions of EV are preferentially located on sun-exposed sites of face, neck, trunk and extremities. The malignant transformation of EV lesions into Squamous Cell Carcinoma occurs in $30-70 \%$ cases; this may require over 20 years for such conversion or occurs when the lesions have been present for 10 years or so, or usually in third and fourth decades of life. ${ }^{12-13}$ Immunological changes occur in patients with this disease, especially in their cellular immunity. These patients show a defect of cell-mediated immunity that is specific toward the causative HPVs. ${ }^{14}$ This deficiency appears to be local and specific, which causes the generation of several cytokines which prevent the immune system from recognizing HPV. This inability to recognize and reject HPVs leads to lifelong lesions/ disease. Interestingly, these EV associated HPVs are also involved in both benign and malignant proliferation of keratinocytes, as in the early stages of carcinogenesis. Hence, the convincing oncogenic potential of HPV 5 and 8 in cutaneous malignancies of EV patients has evoked a considerable interest among clinicians and basic researchers for this rare genetic disorder as a model of cutaneous carcinogenesis.

However, the underlying defect in EV is still not well understood. This susceptibility of human keratinocytes to the HPV in EV is usually inherited through an autosomal recessive gene, and pathogenic mutations have been detected in EVER1/TMC6 and EVER2/TMC8 genes mapped to a locus on chromosome 17q 25 that encodes integral membrane proteins of unknown significance in the endoplasmic reticulum. A high frequency of parental consanguinity is usual in most reported cases, and more than $30 \%$ of the siblings acquire the disease at some or the other stage. The absence of the disorder in either of the parents, unusual for disorders with autosomal dominant inheritance, can be explained on the basis of "lack of penetrance" wherein a person inheriting the defective gene may not develop the disorder. ${ }^{2}$ Nevertheless, cases with autosomal dominant or X-linked inheritance too have been reported. ${ }^{17}$ Mutated EVER1 and EVER2 genes in EV patients may control the infection of other viruses. ${ }^{18}$ It is often associated with IgM deficiency and HIV infection.

The dysplastic and malignant changes in the EV lesions usually occur in the form of actinic keratosis, Bowen's disease or Squamous cell carcinoma having a low metastatic potential. ${ }^{12}$ However, all types of lesions seen in EV patients should be subjected to histopathology for early detection of any malignant changes, as clinically benign appearing lesions can demonstrate atypia. Early identification and appropriate treatment of actinic keratoses is also important as these are increasingly being recognized as an early clinical manifestation of biological continuum that may ultimately lead to invasive Squamous cell carcinoma. $^{2}$

Because Human Papilloma Virus infection is non-lytic, antigen presentation occurs very slowly. HPV infection does not induce inflammatory cytokines therefore, therapeutic options aimed at modulating the immune system and facilitating the production of cytokines have been proposed. ${ }^{19}$ Morbidity and mortality associated with EV may be avoided by early recognition of the disease, sun avoidance, monitoring by a dermatologist, and treatment of premalignant and malignant lesions. Treatment options of epidermodysplasia verruciformis are limited, and to date no specific treatment exists. Treatment aims primarily to prevent the progression of benign lesions to malignancy. Medical management for EV includes topical imiquimod and 5- fluorouracil, systemic retinoids, interferon-alpha, cimetidine, zinc, and combination therapy.

Acitretin 0.5-1 mg/day has been effective and is perhaps the drug of choice currently. ${ }^{20}$

Prescribing zinc is due to its immunomodulatory effects. Zinc is a micronutrient that is necessary for the normal functioning of cells. More importantly, this element modulates DNA and RNA related enzymes and is also involved in many immunologic processes. Kitamura et al. proposed that toll-like receptors mediated regulation of zinc homeostasis which influences dendritic cell function. Zinc may be administered as acetate, gluconate or sulphate, but 
the latter seems to be better tolerated. One $100 \mathrm{mg}$ capsule of zinc sulphate has $22.5 \mathrm{mg}$ of elemental zinc. Normal plasma levels of zinc are $70-110 \mu \mathrm{g} / \mathrm{dl}^{21}$

Cimetidine's inhibitory effect on T- suppressor cell function and ability to depress mitogen-induced lymphocyte proliferation are among the mechanisms by which its usefulness has been justified. ${ }^{22}$

Interferons have been used effectively for the treatment of warts in EV, with their antiviral action and ability to inhibit malignant cell growth and stimulate natural killer cells and T cells. ${ }^{23}$ Genetic counseling and frequent dermatologic monitoring of patients should be undertaken. ${ }^{24}$

These non-surgical modalities, which are only palliative and improve quality of life, need large controlled studies for recommending their lifelong use.
Our patient was unresponsive to the preferred treatment, and hence, he was advised to discontinue oral medications.

Stringent sun protection and lifelong observation for early diagnosis of malignant/premalignant lesions, which then can be treated early with surgical excision/ grafting or ablated locally, is imperative for improved prognosis/survival of EV patients. ${ }^{2}$ The same was advised for the present patient also.

\section{Conclusion}

This case is being reported to bring to light, the unresponsiveness and resistance to known treatment options. There is a need for further investigations of new treatment modalities for EV. Physicians should monitor patients of EV regularly for early detection of malignant transformation.

\section{Refrences}

1. Bhat YJ, Ashraf S, Hassan I. Epidermodysplasia verruciformis in two siblings responding to retinoids. Indian J Paediatr Dermatol 2016; 17: 322-4. https://doi.org/10.4103/23197250.184328

2. Vohra S, Sharma NL, Shanker V, Mahajan VK, Jindal N. Autosomal dominant epidermodysplasia verruciformis: A clinicotherapeutic experience in two cases. Indian J Dermatol Venereol Leprol 2010; 76: 557-61. https://doi.org/10.4103/03786323.69092

3. Sun XK, Chen JF, Xu AE. A homozygous nonsense mutation in the EVER2 gene leads to epidermodysplasiaverruciformis. ClinExpDermatol 2005; 30: 573-4. https://doi. org/10.1111/j.1365-2230.2005.01858.x

4. Roncalli de Oliveira W, Neto CF, Rady PL, Tyring SK. Seborrheic Keratosis-like lesions in patients with epidermodysplasia verruciformis J Dermatol 2003; 30: 48-53.

5. García-Río I, Garcia-F-Villalta MJ, Daudén E, Fraga J, García-Díez A. Epidermodysplasia verruciformis-like lesions in a patient with systemic lupus erythematosus. ActaDermVenereol 2003; 83: 229-30. https:// doi.org/10.1080/00015550310007300

6. Ostrow RS, Manias D, Mitchell AJ, Stawowy L, Faras AJ. Epidermodysplasia verruciformis.A case with primary lymphatic dysplasia, depressed cell-mediated immunity, and Bowen's disease containing human papilloma 16 DNA. Arch Dermatol 1987; 123: 1511-6. https://doi.org/10.1001/ archderm.1987.01660350111025

7. Pfister H. Human papilloma viruses and impaired immunity vs epidermodysplasia verruciformis. Arch Dermatol 1987; 123: 1469-70. https://doi.org/10.1001/ archderm.1987.01660350069015

8. Sehgal VN, Luthra A, Bajaj P. Epidermodysplasiaverruciformis: 14 members of a pedigree with an intriguing squamous cell carcinoma transformation. Int J Dermatol 2002; 41: 500-3. https://doi.org/10.1046/ j.1365-4362.2002.01539.x

9. Shah BH, Jalan VD. Review of literature of epidermodysplasia verruciformis with 2 case reports. Indian J Dermatol Venereol Leprol 1971; 37: 16-8.

10. Singh OP, Nayyar KC. Epidermodysplasia verruciformis. Indian J Dermatol Venereol Leprol 1973; 39: 26-8.

11. Vasishtha LK. Condylomata accuminata like lesions in epidermodysplasia verruciformis. Indian J Dermatol Venereol Leprol 1981; 47:2 29-31. 
12. Gül U, Kiliç A, Gönül M, Cakmak SK, Bayis SS. Clinical aspects of epidermodysplasia verruciformis and review of the literature. Int J Dermatol 2007; 46: 1069-72. https://doi. org/10.1111/j.1365-4632.2006.03014.x

13. Jablonska S, Majewski S. Skin autograft in epidermodysplasia verruciformis: human papilloma virus associated cutaneous changes need over 20 years for malignant conversion. Cancer Res 1997; 57: 4214-6.

14. Bhutoria B, Shome K, Ghosh S, Bose K, Datta C, Bhattacharya S. Lewandowsky and lutz dysplasia: Report of two cases in a family. Indian J Dermatol 2011; 56: 190-3. https://doi. org/10.4103/0019-5154.80414

15. Favre M, Majewski S, Noszczyk B, Maienfisch F, Pura A, Orth $G$, et al. Antibodies to human papillomavirus type 5 are generated in epidermal repair processes. J Invest Dermatol 2000; 114: 403-7. https://doi.org/10.1046/ j.1523-1747.2000.00892.x

16. Aochi S, Nakanishi G, Suzuki N, Setsu N, Suzuki $D$, Aya $K$, et al. A novel homozygous mutation of the EVER 1/TMC6 gene in a Japanese patient with epidermodysplasia verruciformis. Br J Dermatol 2007; 157: 1265-6. https://doi. org/10.1111/j.1365-2133.2007.08206.x

17. Androphy EJ, Dvoretzky I, Lowy DR. Xlinked inheritance of epidermodysplasia verruciformis. Genetic and virologic studies of a kindred. Arch Dermatol 1985; 121: 864-8. https://doi.org/10.1001/ archderm.1985.01660070054014
18. Frecha C, Chevalier SA, van Uden P, Rubio I, Siouda M, Saidj D, et al. Expression of the epidermodysplasia verruciformis-associated genes EVER 1 and EVER 2 is activated by exogenous DNA and inhibited by LMP1 oncoprotein from Epstein-Barr virus. J Virol 2015; 89: 1461-7. https://doi.org/10.1128/ JVI.02936-14

19. Parton AM, Sommerville RG. The treatment of plantar verrucae by triggering cell-mediated immunity. Br J Pod Med 1994; 131: 883-6.

20. Lutzner MA, Blanchet-Bardon C. Epidermodysplasia verruciformis. CurrProblDermatol 1985;13:164-85.

21. Kitamura H, Morikawa $H$, Kamon H, Iguchi M, Hojyo S, Fukada T, et al. Toll-like receptormediated regulation of zinc homeostasis in uences dendritic cell function. Nat Immunol 2006; 7: 971-7. https://doi.org/10.1038/ ni1373

22. Micali G, Nasca MR, Dall'Oglio F, Musumeci ML. Cimetidine therapy for epidermodysplasia verruciformis: J AmAcad of Dermatol 2003; 48: S9-10. https://doi.org/10.1067/mjd.2003.111

23. Silva CS, Ramos RO, Pires MC, Sittart JAS. Epidermodisplasia verruciforme: tratamento combinado com acitretina e interferon alfa-2a. An Bras Dermatol. 2006; 81: 595-7. https://doi. org/10.1590/S0365-05962006000600013

24. Meissner MCG, Gon AS, Bedrossian AAD, Sonnberger JCN, Reis CRC. Epidermodisplasia verruciforme: relato de caso. An Bras Dermatol. 2005; 80: S77-188. 